\title{
Predominance of sexual reproduction in Romanian populations of the aphid Sitobion avenae inferred from phenotypic and genetic structure
}

\author{
D Papura, J-C Simon, F Halkett, F Delmotte, J-F Le Gallic and C-A Dedryver \\ INRA/ENSAR, Unité Mixte de Recherche 'Biologie des Organismes et des Populations Appliquée à la Protection des Plantes' (BiO3P), \\ BP 35327, F-35653 Le Rheu Cedex, France
}

\begin{abstract}
Models of coexistence of sexual and asexual lineages in aphids assume that obligate parthenogenetic lineages predominate in areas with mild winter climate because of their high reproductive output, while sexual lineages predominate in areas with severe winter because they produce eggs resistant to frost. To validate this hypothesis in natural conditions, the reproductive mode of populations of the aphid Sitobion avenae was assessed in two very contrasting climatic situations, Romania (severe winter) and Western France (mild winter). To achieve this, reproductive modes were inferred from both (1) the population composition in sexual and asexual forms in autumn, and (2) the genetic structure of Romanian and French populations of $S$. avenae
\end{abstract}

using microsatellite markers. Romanian populations encompassed a high proportion of sexual forms and were characterised by a very high genotypic diversity and low linkage disequilibrium. In constrast, the French population showed frequent linkage disequilibria, low genetic diversity, and high level of clonal amplification with two asexual genotypes representing over $60 \%$ of the sample. In agreement with the model's predictions, these results clearly indicate that sexual reproduction in $S$. avenae is predominant under the continental climate of Romania, while asexual lineages prevail under the oceanic climate of Western France.

Heredity (2003) 90, 397-404. doi:10.1038/sj.hdy.6800262

Keywords: sexual forms; microsatellites; evolution of sex; geographic parthenogenesis; climate

\section{Introduction}

Parthenogens tend to have a geographical and ecological distribution that is different from their sexual relatives, a pattern known as geographical parthenogenesis (Vandel, 1928). Generally, these distributions are associated with spatial patterning of selection pressures because of biotic and abiotic factors, especially climatic ones (Lynch, 1984). Several hypotheses have been proposed to account for geographical parthenogenesis (reviewed in Lynch, 1984; Parker and Niklasson, 1999). The first set of hypotheses assumes that there are no qualitative differences between sexual and parthenogenetic genotypes other than their reproductive capacity and their level of genetic diversity. This is true, for example, in the case of the Tangled bank model, which assumes that genetically variable sexual populations dominate heterogeneous environment, while less variable parthenogenetic ones dominate more stable habitats (Bell, 1982). In the second set of hypotheses, parthenogenetic and sexual genotypes are qualitatively different in phenotypic responses. The general-purpose hypothesis, which predicts selection for asexual generalist or 'general-purpose' genotypes with broad environmental tolerance and low temporal

Correspondence: J-C Simon, INRA/ENSAR, Unité Mixte de Recherche 'Biologie des Organismes et des Populations Appliquée à la Protection des Plantes' (BiO3P), BP 35327, F-35653 Le Rheu Cedex, France.

E-mail: jcsimon@rennes.inra.fr

Received 26 July 2002; accepted 29 January 2003 variance in fitness, falls into this second class of explanations (Baker, 1965; Lynch, 1984). However, there are few biological systems that allow testing of these hypotheses and even fewer in which breeding system variation is not confounded by ploidy level shifts (Mogie, 1986; Dufresne and Hebert, 1994). Aphids are useful models for assessing the extent of geographic parthenogenesis because they display reproductive mode polymorphism and are strict diploids.

Cyclical parthenogenesis, which consists in the alternation of several parthenogenetic generations and a single sexual generation, is the ancestral life cycle of aphids (Moran, 1992). Transitions to permanent asexuality are frequent in aphids leading to the coexistence of cyclical and obligate parthenogenetic lineages (CP and OP lineages, respectively) in the same species, for example, the Peach-potato aphid, Myzus persicae (Blackman, 1971) and the English grain aphid, Sitobion avenae (Dedryver et al, 1998). Four major reproductive strategies have been described in field-collected clones of these species: (1) CP lineages retain a full commitment to sexual reproduction once a year, with generations of asexuality followed by the production of only males and females that lay fertilised eggs in the autumn, (2) intermediate lineages reproduce sexually once a year but also continue to produce parthenogenetic individuals in autumn and through the winter, (3) OP lineages reproduce by continuous parthenogenesis, and (4) a special class of OP reproduce by continuous parthenogenesis but retains the ability to produce males (Blackman, 1971; Dedryver et al, 1998). 
Fertilised eggs, produced either by CP or intermediate lineages, are the only frost-resistant life stage. In contrast, OP lineages are susceptible to freezing conditions. Theoretical models of sexual and asexual coexistence in aphids have shown that, because of this ecological difference, the local balance between life cycles (CP, OP, and intermediates lineages) should be determined by the winter climate, with OP and intermediates dominating in mild winter regions, $\mathrm{CP}$ in cold winter regions, and a mixture of the three in intermediate climates (Rispe et al, 1998; Rispe and Pierre, 1998). Validation of this hypothesis could be realised directly, in natural conditions, by investigating the population composition of sexual and asexual morphs in the autumn. For $S$. avenae, sexual morphs have rarely been detected in the field in Western Europe (Hand, 1983, 1989; Dedryver, 1987); thus direct investigation of sexual reproduction has been mostly unsuccessful. However, the response in laboratory to sexinducing conditions of field-collected clones from different regions of Western Europe demonstrates the expected link between the level of investment in sexual reproduction and the local winter climate. Indeed, sexual reproduction dominates in lineages of $S$. avenae from north of Western Europe (Newton and Dixon, 1988; Dedryver et al, 2001), whereas asexual reproduction dominates in lineages from Southwestern Europe (Pons et al, 1995; Dedryver et al, 2001). However, such indirect evidence may not exactly reflect the actual investment in sexual reproduction in the field.

Recently, the reproductive modes of $S$. avenae have been inferred from the genetic structure of natural populations using microsatellites. The high genotypic diversity and conformation to Hardy-Weinberg equilibrium (HWE) detected in British populations of this aphid suggested that they are dominated by lineages investing in sexual reproduction (Sunnucks et al, 1997). However, similar studies on French populations did not lead to clearcut results on the geographical distribution of CP and OP lineages (Simon et al, 1999). Although Northern and Southern French populations of S. avenae are genetically differentiated, probably as the result of differences in breeding systems, other factors may also account for this geographic partitioning.

Overall, these indirect methods seem to give support to the theoretical models mentioned above (Rispe et al, 1998; Rispe and Pierre, 1998), but only a comparison of more contrasted climatic situations, covering constantly mild and severe winter climates, could fully ascertain the hypothesis of selection by winter climate of reproductive modes in aphids. Here we examine both phenotypic and genetic variation in Romanian (severe winter climate) populations of $S$. avenae and compare the genetic parameters with those of a population from Western France (mild winter climate). We expect that in Central Europe, under continental climatic conditions, sexual reproduction is strongly selected by long freezing periods, while in mild Western France, permanent asexual reproduction is more likely to predominate.

\section{Material and methods}

\section{Aphid collections}

In Romania, aphids were collected from three sites in the West of the country (Timisoara, Recas, and Becicherec,

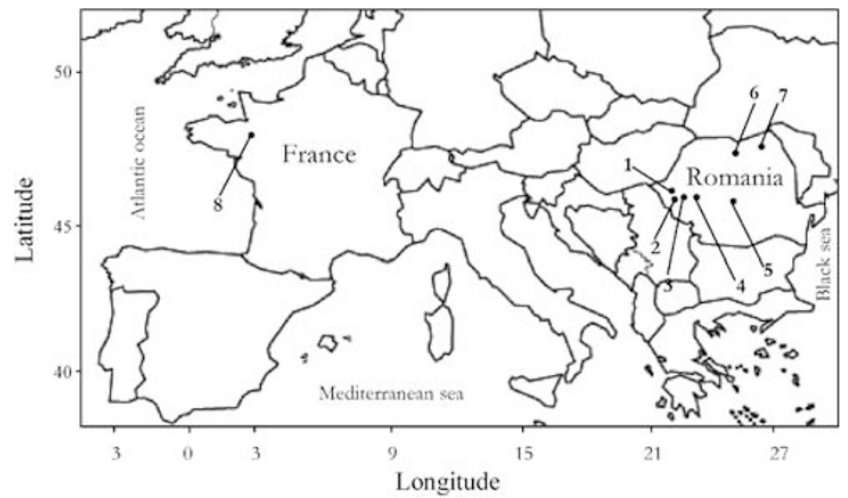

Figure 1 Locations of the populations of $S$. avenae collected in Romania (October 1998, 1999) and in France (July 1999). Populations have been labelled as follows: 1, Becicherec; 2, Timisoara; 3, Recas; 4, Lugoj; 5, Sibiu; 6, Bistrita; 7, Suceava (Romania), and 8, Rennes (France).

Figure 1) from September 1998 to January 1999 and from September 1999 to January 2000. Four additional samples were collected at the end of October 1999 in Central (Lugoj and Sibiu) and Northern Romania (Bistrita and Suceava) (Figure 1). Aphids were collected from a range of host plants including barley, wheat, maize, and ryegrass. Each aphid was sampled from different plants, separated from each other by more than $1 \mathrm{~m}$ to minimise the risk of collecting the same clone. The morph of each Romanian aphid $(N=580)$ was then distinguished (see below). A subsample of these aphids $(N=238)$ including all males and a high proportion of mating females was used for the genetic analysis. Samples from the same site and period of time were considered a single 'population', so that 10 populations were analysed for Romania.

In France, a single population $(N=182)$ was collected in the West of the country (Rennes, Britanny) from maize fields in the beginning of July 1999 and was used for the genetic analysis only.

Determination of sexual and parthenogenetic morphs Aphids were collected directly into 95\% ethanol, and subsequently identified in the laboratory. Some $S$. avenae morphs can be distinguished using a morphological characters key. Wingless sexual females were identified by the presence of scent glands on tibia III and males by their black sclerotic external genitalia (Miyazaki, 1987). Winged parthenogenetic females, which could be mothers of mating females or mothers of parthenogenetic females, cannot be separated by morphological traits. Wingless parthenogenetic females sampled at this period of the year were considered to be mothers of parthenogenetic females.

The 580 aphids sampled in Romania were assigned to three different morph classes: (i) a class of sexual morphs including mating females and males (SM), (ii) a class of winged parthenogenetic females (WPF), which is composed of WPF mothers and mating female mothers, and (iii) a class of wingless (apterous) parthenogenetic females (APF). We expect that between October and December, the SM class is comprised of CP clones, the WPF class by a mix of CP and OP clones, and the APF class by OP clones (Dedryver et al, 1998). However, 
intermediate lineages that produce both SM along with parthenogenetic females in the autumn will also be found in each of these three classes of morphs.

Following morph determination, aphids were placed in individual Eppendorf tubes and stored at $-80^{\circ} \mathrm{C}$ awaiting DNA extraction and microsatellite analysis.

\section{Microsatellite genotyping}

Total DNA was extracted from individual aphids using a salting-out protocol (Sunnucks and Hales, 1996). Each aphid was genotyped using five microsatellite loci: four of these (Sm10, Sm17, S16b, and S17b) were isolated from S. miscanthi (Sunnucks et al, 1996; Simon et al, 1999; Wilson et al, 1999), and one (S5L) was isolated from $S$. avenae (Simon et al, unpublished).

Microsatellite loci were amplified in a final volume of $15 \mu \mathrm{l}$ using 3 pmol of each primer, $50 \mu \mathrm{M}$ of each dNTP, $1.5 \mu \mathrm{l}$ of $10 \times \mathrm{Mg}^{2+}$ free reaction buffer $(500 \mathrm{mM} \mathrm{KCl}$, $100 \mathrm{mM}$ Tris-HCl pH 9.0, and 1.0\% Triton X-100), $2 \mathrm{mM}$ of $\mathrm{MgCl}_{2}, 0.5 \mathrm{U}$ of Taq DNA polymerase (Promega), and $1 \mu \mathrm{l}$ of DNA $(5 \mathrm{ng})$. PCR reactions were performed in a PCR Express machine (Hybaid, Inc.) with a regime of initial denaturation at $94^{\circ} \mathrm{C}$ for $2 \mathrm{~min}$ followed by 35 cycles of denaturation at $94^{\circ} \mathrm{C}$, annealing temperature depending on locus, and elongation at $72^{\circ} \mathrm{C}$, each for $40 \mathrm{~s}$. PCR products were run on $1.4 \%$ agarose gels to check for amplification. Microsatellite products were then loaded onto a denaturing polyacrylamide gel and visualized by silver staining as described in Haack et al (2000). Allele sizes were estimated using a sequencing size ladder (sequence of pGEM - 3Zf(+) vector PROMEGA).

\section{Genetic data analysis}

Since clonal amplification of a genotype can impact data interpretation (Sunnucks et al, 1997), analyses were performed on microsatellite data either with all individuals or with one representative of each genotype (ie clonal copies removed). This approach had little effect in Romanian populations because the few identical genotypes (only 15) have a low probability to derive from independent recombination events $(P=0.0001)$, hence resulted more likely from clonal amplification. Similarly, it had little effect on parameter estimations and no effect on the significance of statistical tests in the French population collected on maize as previously found by Haack et al (2000). Thus, we will present only results from statistical tests with one copy per genotype for both Romanian and French populations.

Allele frequencies and unbiased heterozygosity (Nei, 1978) were calculated for each sample. Before testing for deviations from HWE, genotypic proportions and global linkage disequilibrium between pairs of loci were tested using the exact tests in GENEPOP version 3.1b (Raymond and Rousset, 1995). Deviations from HWE expectations and unbiased estimates of $F_{\text {IS }}(f)$ (Weir and Cockerham, 1984) were estimated using FSTAT version 2.9.1 (Goudet, 1995) permuting alleles 1000 times among individuals. Sequential Bonferroni corrections were used to compute tablewide significance levels for simultaneous statistical tests (Rice, 1989).

Population structure inferred from microsatellite loci was assessed by calculating $F_{\mathrm{ST}}(\theta)$ (Weir and Cockerham, 1984) between populations and tested by randomising multilocus genotypes between each pair of samples using FSTAT 2.9.1. Pairwise $F_{\mathrm{ST}}$ values were computed using GENEPOP 3.1b. These F-statistics were then tested for significance by performing 5000 permutations of alleles or genotypes in FSTAT 2.9.1. A hierarchical analysis of molecular variance (AMOVA, Excoffier et al, 1992) including Romanian populations within host plant groups (barley, $N=115$; wheat, $N=57$; maize, $N=33$; ryegrass, $N=33$ ) was performed using ARLEQUIN version 2.000 (Schneider et al, 2000). Host plant effect could not be analysed in France because all aphids were collected on maize.

For all populations, isolation by distance (IBD) was tested as suggested by Rousset (1997). The Mantel test for significance of the correlation between geographical and genetic matrices was performed using GENEPOP 3.1b.

To investigate relation between morph classes (mating females, males, and parthenogenetic females) in Romania, their level of genetic differentiation was computed using GENEPOP 3.1b. Cavalli-Sforza and Edwards chord distance were calculated between the morph classes using POPULATION version 1.2.01 (http://www.cnrsgif.fr/pge/bioinfo).

\section{Results}

\section{Genic and genotypic diversity}

Substantial genetic variation was found across Romanian populations. Allelic diversity at the five microsatellite loci ranged from three to 21 alleles per locus with 54 alleles identified across all loci. Mean observed heterozygosity ranged from 0.285 to 0.647 and averaged 0.417 over all loci. A total of 223 multilocus genotypes were detected in the 238 Romanian aphids, on the basis of the five microsatellites. In all, $94 \%$ of Romanian genotypes were sampled once and only seven genotypes were found multiple times: two of them were sampled six and five times, respectively, and the other five genotypes were identified in two or three copies. These seven multicopy genotypes were found only in the three western Romanian sites and only three of them were sampled in both years. They were wingless and winged parthenogenetic females; no sexual morphs presented multicopy genotypes.

In Western France, only 51 genotypes were uncovered among 182 aphids tested. Two genotypes were very frequent. They were found 93 and 17 times, respectively, and represented more than $60 \%$ of the sample. Seven other genotypes were found in lower copy numbers (two to nine copies) and 42 genotypes were found only once. A total of $67 \%$ of alleles were shared between Romanian and French populations but no genotype was shared among the two countries. In all, $80 \%$ of unshared alleles were specific to Romanian populations, and were found at relatively low frequencies (0.006-0.046) in the sexual morphs (mating females and males) and in the winged parthenogenetic females.

\section{Analysis of linkage disequilibrium}

An exact test for linkage disequilibrium (LD) in Romanian populations showed two significant pairs out of 100. Significant LD was observed between S5L and Sm10 in Becicherec in $1998(P<0.001)$, and between S17b and S16b in Timisoara in $1998(P<0.001)$. There were no significant disequilibria in Romanian popula- 
Table 1 Comparison of genetic parameters calculated across Romanian and French populations sampled in 1999 and based on five microsatellite loci

\begin{tabular}{lcc}
\hline Tests & Romania & France \\
\hline$N_{\mathrm{i}}$ & 134 & 182 \\
$N_{\mathrm{g}}$ & 130 & 51 \\
$N_{\mathrm{i}} / N_{\mathrm{g}}$ & 0.97 & 0.28 \\
Mean nb of allele/locus & 8.8 & 7.63 \\
Ho (SE) & $0.417(0.112)$ & $0.686(0.180)$ \\
$P$ deficit & $*$ & $\mathrm{NS}$ \\
$P$ excess & $\mathrm{NS}$ & $*$ \\
$F_{\mathrm{IS}}$ multilocus & $0.316^{*}$ & $-0.278^{*}$ \\
$\mathrm{LD}$ & $0 / 10$ & $5 / 10$ \\
\hline
\end{tabular}

$N_{\mathrm{i}}$ : number of individuals; $N_{\mathrm{g}}$ : number of genotypes; Ho (SE): mean observed heterozygosity (standard error); $P$ deficit: probability that $\mathrm{Ho}<\mathrm{He}$; $P$ excess: probability that $\mathrm{Ho}>\mathrm{He}$; LD: pairs of loci in significant linkage disequilibrium $(P<0.05)$. NS : non significant $(P>0.05)$; *: significant $(P<0.001)$.

tions in 1999 (Table 1). The French population showed significant LD at five out of 10 locus pairs: three between S16b and each of S5L, Sm10, S17b $(P<0.001)$ and two between S5L and each of Sm10, S17b $(P<0.01)$ (Table 1).

\section{Genetic structure within populations}

In Romanian populations, the mean number of alleles per population ( $>20$ individuals) ranged from 5 to 7.4 . For all populations, observed heterozygosity ranged from 0.285 to 0.671 and was always lower than expected heterozygosity. This was reflected in positive and significant multilocus $F_{\text {IS }}$ that ranged from 0.062 to 0.492. In contrast, the French sample was in significant heterozygote excess leading to negative and significant multilocus $F_{\text {IS }}$ (Table 1).

\section{Genetic differentiation between Romanian populations} Differentiation between Romanian populations quantified by multilocus $F_{\mathrm{ST}}$ was significant $\left(F_{\mathrm{ST}}=0.0027\right.$, $P<0.01)$. Yet, the matrix of pairwise multilocus $F_{\mathrm{ST}} /(1-$ $F_{\mathrm{ST}}$ ) estimates for Romanian populations was not significantly correlated with that of geographical distances (Mantel test, $P=0.25$ ). A significant isolation by distance was observed, however, when the French population was included $\left(F_{\mathrm{ST}}=0.030, P<0.005\right.$; Mantel test, $P=0.025)$. This pattern was mainly attributable to locus S17b (Mantel test, $P=0.008$ ).

\section{Genetic differentiation in relation to host plant}

In Romania, no genotype was collected more than once on the same host plant. Moreover, genotypes collected on the same host plant were not genetically more related to each other than were genotypes from different host plants (data not shown). The analysis of molecular variance showed that most of the microsatellite variability was distributed within populations $(96.6 \%)$, while a negligible part of the variance was because of differences between populations (3.37\%) and differences among host plants $(0.03 \%)$. Indeed, genetic differentiation between host plants was not significantly different from $0\left(F_{\mathrm{ST}}=0.0001 ; P=0.66\right)$.

\section{Morph composition in Romanian populations}

In Romania, the number of the different morphs of $S$. avenae per plant followed a unimodal curve in both 1998 and 1999. At the end of October 1998 and 1999, mating females represented 38 and $20.3 \%$, respectively, of the total number of aphids sampled. The presence of males in field aphid collections was observed in October of each year, reaching a maximum of $6.2 \%$ in 1998, and 7.7\% in 1999, of the total number of aphids sampled (Figure $2 a, b)$.

\section{Comparison of genetic structure between morphs}

The genetic structure between morphs was compared to test whether sexual forms (SM) were produced by cyclically parthenogenetic lineages, APF by obligately parthenogenetic lineages and WPF by a mix of both. No LD was found in the SM class, nor in the WPF class; so independent assortment was assumed in these classes. By contrast, the APF class had 3/10 pairs of loci (S5LSm10, Sm10-S17b, and Sm17-S16b) in linkage disequilibrium $(P<0.001)$.

There were deviations from Hardy-Weinberg proportions for each of the three classes but not in the same direction. For both the SM and WPF classes, the samples were in significant heterozygote deficit. By contrast, the APF class was in significant heterozygote excess. Overall, $F_{\text {IS }}$ was inversely proportional to the degree of sexual reproduction reflected by the composition in sexual and parthenogenetic morphs (Table 2).

The genetic relatedness of the different $S$. avenae morphs assessed by the Cavalli-Sforza and Edwards (1967) chord distance and genetic differentiation tests gave similar results. Both the SM and WPF classes were rather distant from the APF class. The WPF was at some loci significantly distant from SM, but on average closer from SM than APF (Table 3).

A major difference was observed in allele frequencies between the three classes of morphs at locus S17b. Frequency of alleles $S 17 \mathrm{~b}^{215,217}$ decreased from SM to APF class, wherever alleles S17b ${ }^{199,209}$ decreased from APF to SM class (Figure 3). Moreover, a similar distribution was observed between Northern and Western Romanian populations: frequency of allele $S 17 b^{215}$ decreased from North (where winters are colder than in Western Romania) to West, and vice-versa for alleles

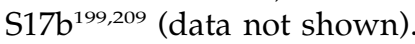

\section{Discussion}

\section{Predominance of sexual reproduction in Romanian S. avenae populations}

The high proportion of sexual morphs (mating females and males) found in Romanian populations of S. avenae in autumn, which has never been observed in the field before (Hand, 1983, 1989; Dedryver, 1987), indicates that sexual reproduction in this aphid prevails in Romania. Genetic structure analysis of the three morph classes (sexual forms, winged and wingless parthenogenetic females) allowed us to estimate the proportion of sexual/ asexual lineages present in Romanian populations. LD, a useful indicator for clonal selection during the parthenogenetic phase, was absent in sexuals and winged parthenogens, whereas it was found in wingless parthenogens, which included most of the multicopy geno- 


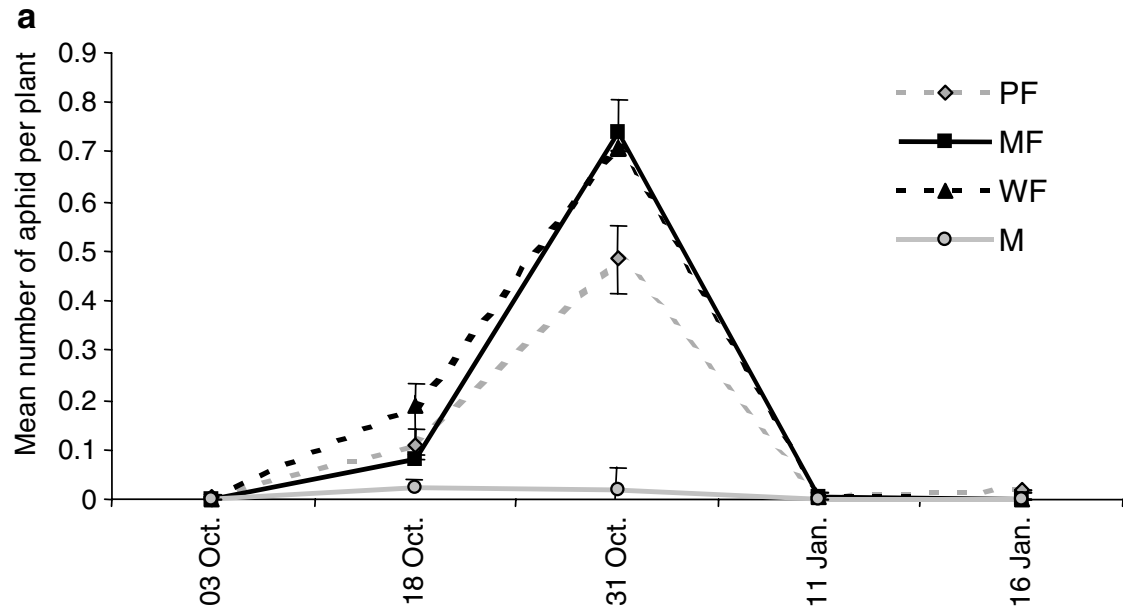

1999

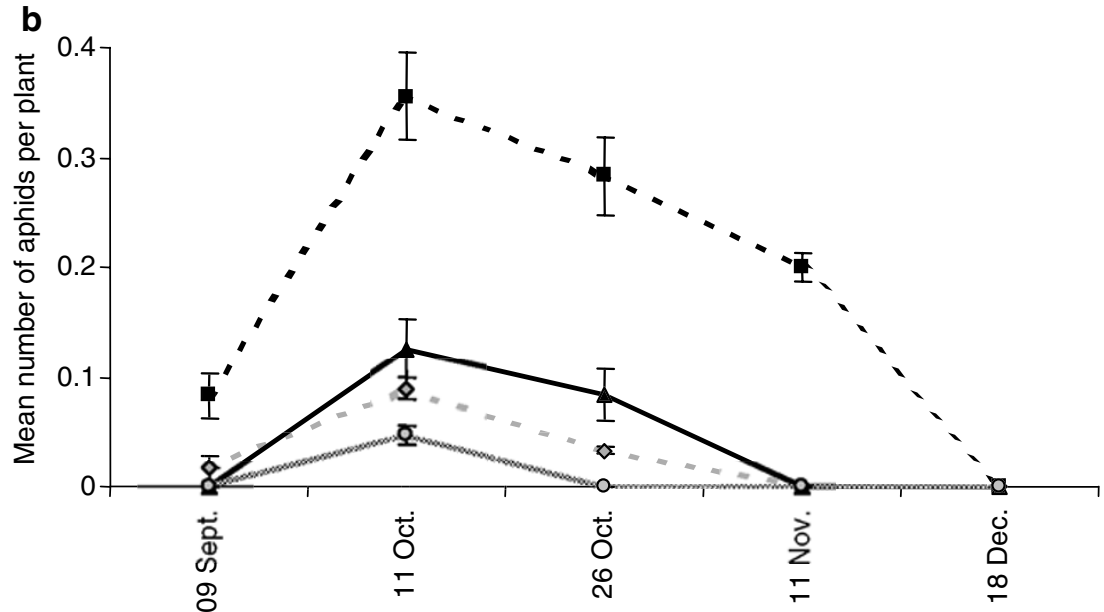

Figure 2 Comparison in sexual and parthenogenetic morphs of Romanian populations of $S$. avenae during autumn and winter $1998(N=433)$ (a) and $1999(N=147)(b)$. PF: parthenogenetic females, MF: mating females, WF: winged females, and M: males.

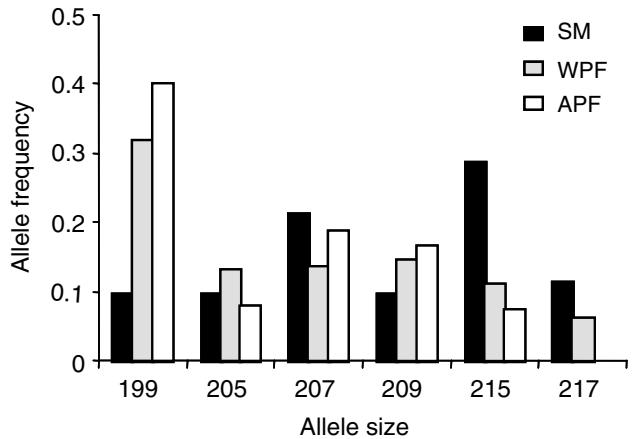

Figure 3 Frequencies of alleles at the locus S17b across Romanian populations for sexual morphs (SM), winged parthenogenetic females (WPF), and wingless parthenogenetic females (APF).

types. Although all classes probably included intermediate lineages that are able to produce both SM along with parthenogenetic females in the autumn, these results suggested that the sexual class was essentially produced by CP lineages while the wingless parthenogens class mainly included permanent OP lineages. The low genetic differentiation together with the close genetic relatedness between the sexual and winged parthenogens classes, suggests that the winged parthenogens class includes a high proportion of CP lineages. As the sexual and winged parthenogens classes represent $80 \%$ of all genotypes sampled, this is further evidence that sexual lineages dominate in Romania although they coexist with asexual and intermediate lineages.

Very high genetic diversity was found in Romanian $S$. avenae populations with $94 \%$ of sampled individuals having different genotypes. It is noteworthy that this is the highest genotypic diversity ever found in this species to date. In addition, Romanian populations were characterised by a very low LD. High genotypic diversity with many different combinations of the same alleles and low linkage disequilibria are likely to be resulting from genetic recombination. Since genetic recombination is unlikely to occur during parthenogenetic reproduction (Sunnucks et al, 1997), this is another strong evidence for the predominance of sexual reproduction in Romania. 
Table 2 Single-locus probability test of deviation from HWE. $F_{\text {IS }}$ values (Weir and Cockerham, 1984). Mean number of alleles/locus (A) and observed $(\mathrm{Ho})$ and expected $(\mathrm{He})$ heterozygosities of the three morph classes found in Romanian populations of Sitobion avenae

\begin{tabular}{|c|c|c|c|c|c|c|c|c|c|c|c|c|c|c|c|}
\hline \multirow[t]{3}{*}{ Classes of morphs } & \multirow[t]{3}{*}{$\mathrm{N}$} & \multirow[t]{3}{*}{ Ho (SE) } & \multirow[t]{3}{*}{$\mathrm{He}(S E)$} & \multirow[t]{3}{*}{ A } & \multicolumn{10}{|c|}{ Microsatellite loci } & \multirow{3}{*}{ Multilocus $\mathrm{F}_{I S}$} \\
\hline & & & & & \multicolumn{2}{|c|}{$S 5 L$} & \multicolumn{2}{|c|}{$\operatorname{Sm} 10$} & \multicolumn{2}{|c|}{$S 17 b$} & \multicolumn{2}{|c|}{$\operatorname{Sm} 17$} & \multicolumn{2}{|c|}{$S 16 b$} & \\
\hline & & & & & $\mathrm{F}_{I S}$ & $\mathrm{P}$ & $\mathrm{F}_{I S}$ & $\mathrm{P}$ & $\mathrm{F}_{I S}$ & $\mathrm{P}$ & $\mathrm{F}_{I S}$ & $\mathrm{P}$ & $\mathrm{F}_{I S}$ & $\mathrm{P}$ & \\
\hline Sexual morphs & 34 & $\begin{array}{c}0.471 \\
(0.065)\end{array}$ & $\begin{array}{c}0.569 \\
(0.130)\end{array}$ & 7.0 & 0.026 & NS & 0.235 & $* *$ & 0.549 & $* * *$ & 0.064 & NS & 0.412 & $* * *$ & 0.294 \\
\hline $\begin{array}{l}\text { Winged asexual } \\
\text { females }\end{array}$ & 145 & $\begin{array}{l}0.478 \\
(0.119)\end{array}$ & $\begin{array}{l}0.537 \\
(0.098)\end{array}$ & 9.0 & 0.03 & NS & 0.081 & * & 0.635 & $* * *$ & 0.042 & NS & 0.375 & $* * *$ & 0.264 \\
\hline $\begin{array}{l}\text { Wingless asexual } \\
\text { females }\end{array}$ & 44 & $\begin{array}{c}0.650 \\
(0.105)\end{array}$ & $\begin{array}{c}0.602 \\
(0.139)\end{array}$ & 6.7 & -0.1 & NS & -0.02 & NS & 0.393 & $* * *$ & -0.03 & NS & 0.257 & $* * *$ & 0.119 \\
\hline
\end{tabular}

${ }^{* * *} P<0.005,{ }^{* *} P<0.01,{ }^{*} P<0.05$. NS: nonsignificant; SE: standard error.

Table 3 Cavalli-Sforza and Edwards (CSE) genetic distance and genetic differentiation between the three classes of $S$. avenae morphs collected in Romania in 1998 and 1999

\begin{tabular}{lccccccc}
\hline \multirow{2}{*}{$\begin{array}{l}\text { Pairwise class } \\
\text { comparison }\end{array}$} & $\begin{array}{c}\text { CSE genetic } \\
\text { distance }\end{array}$ & \multicolumn{6}{c}{ Loci } \\
\cline { 3 - 7 } & & S5L & Sm10 & S17b & Sm17 & S16b \\
\hline SM and APF & 0.265 & NS & $* *$ & $* * *$ & $* *$ & $* *$ \\
SM and WPF & 0.194 & NS & $*$ & $* * *$ & NS & NS \\
WPF and APF & 0.206 & $*$ & $*$ & $*$ & $* *$ & $*$ \\
\hline
\end{tabular}

SM: sexual morphs; APF: apterous parthenogenetic females; WPF: winged parthenogenetic females. NS: nonsignificant; ${ }^{* * *} P<0.0005$, $* * P<0.005, * P<0.05$.

In contrast with Romanian populations, there is growing evidence from this and earlier studies that populations of Western France do not invest that much in sexual reproduction. First, long-time series of records (1975-1985) of S. avenae populations in Brittany failed to detect sexual forms in the field during autumn (Dedryver, 1987). As well, although the French population of $S$. avenae was not sampled at the time of sexual reproduction (autumn) in 1999 (which makes difficult to compare French and Romanian populations in our work), we know from another study that sexual forms were not found in Western France populations from maize fields in the two preceding autumns (Haack et al, 2000). Second, we have shown here that two genotypes were highly frequent in the Western France population of S. avenae, representing over $60 \%$ of the sample. These two genotypes correspond to two predominant clones previously identified in the same region for the two previous years (Haack et al, 2000). The fact that, for three consecutive years (1997-1999) (Haack et al, 2000, present study), these two clones were in high (over $50 \%$ for the three years) and stable frequencies over seasons (no change between spring, summer, and autumn 1997 and 1998) and years (no change between 1997, 1998, and 1999) strongly suggests that they have persisted successfully as asexuals for at least 3 years with no or little temporal variation in this area of France. These temporal stabilities in genetic structure and predominance of asexual genotypes were confirmed at the population level since heterozygosities in Western France popula- tions of $S$. avenae did not vary largely between seasons (eg 0.672 and 0.646, respectively for the end of winter and summer 1998) and years (eg 0.646 and 0.686, respectively, for summers 1998 and 1999) (see Haack et al, 2000 for 1997 and 1998 data, present study for 1999 data) and were always within the range of those typically found for asexual populations of this species (Simon et al, 1999).

The alternation of sex and parthenogenesis as reproductive modes exerts a profound impact on the genetic structure of CP populations (Hebert, 1987; Carvalho, 1994). During the parthenogenetic phase, clonal selection amplifies well-adapted genotypes, causing an erosion of clonal and phenotypic diversity (Lynch and Spitze, 1994; Deng and Lynch, 1996). The subsequent over-representation of some genotypes will cause genetic variation to become highly structured, with the appearance of linkage disequilibria and/or deviation from HWE. As Romanian aphids were sampled at the end of the parthenogenetic phase, clonal selection should have eroded the genotypic diversity of $S$. avenae populations (De Barro et al, 1995; Dedryver et al, 1998; Haack et al, 2000). However, the very low clonal amplification, high genetic variability, and low linkage disequilibria found in Romanian populations suggest that selection acting during their parthenogenetic phase is rather weak.

\section{Validation of theoretical models}

Following models of the coexistence of sexual and asexual aphid lineages under mild winters (Rispe et al, 1998; Rispe and Pierre, 1998), OP lineages have the advantage of their high reproductive output while under severe frosts, sexual reproduction is the only successful strategy. Thus, OP and intermediate lineages may be prevalent in mild winter regions, while cold winter regions are expected to be dominated by $\mathrm{CP}$ lineages. In agreement with this hypothesis, we found that the French population (mild winter climate) appeared to be dominated by OP lineages. In contrast, in the severe continental climatic conditions of Romania, CP lineages were clearly dominating.

However, in Romania, there appeared to be a minority of OP lineages that should be strongly counterselected by winter temperatures below $-10^{\circ} \mathrm{C}$ (Dixon, 1985; Newton and Dixon, 1988; Hand, 1989) that regularly occur in this 
country. Thus, the persistence of some OP lineages through 1998 and 1999 in Romania is puzzling. This pattern could be explained by long-distance migration of aphids from warmer regions. It is noteworthy that longdistance migration of OP lineages has already been suggested between Spain and England in this aphid species (Loxdale et al, 1985). Similarly, OP lineages of another cereal aphid, $R$. padi, were found over a very large geographic area including Romania, Syria, and France (Delmotte et al, unpublished data).

\section{Heterozygosity in Romanian and French $S$. avenae populations}

Romanian populations showed a heterozygote deficit, which seems typical of cyclical parthenogenetic cereal aphid populations (Simon et al, 1999; Delmotte et al, 2002). As expected, heterozygosity decreased with the degree of sexuality associated with the three morph classes. Heterozygote deficits in sexual lineages can result from several effects such as substructure within the sample, inbreeding, or selection. For instance, inbreeding could result from assortative mating: a form of de facto assortative mating resulting from differences in habitat choice has been reported in aphids (Caillaud and Via, 2000). In the case of $S$. avenae, however, assortative mating would require differences in mating behaviour of clones (genotypes), of which no evidence exists so far. Heterozygote deficit could also result from population subdivision within sexual populations (Wahlund effect). However, long-range dispersal and ubiquitous host access should reduce the influence of this phenomenon. Selection has been advocated by Sunnucks et al (1997) and Simon et al (1999) to explain heterozygote deficit in sexual lineages of $S$. avenae. Indeed, sexual populations have the potential to generate a diversity of genotypes on which selection could act, leading to an increase of $\mathrm{CP}$ lineages homozygous for favoured alleles (Hales et al, 1997).

By contrast, the Romanian wingless parthenogens and the French population showed significant heterozygote excess. As neutral allele sequence divergence tends to increase rapidly in OP lineages that accumulate mutations (Birky, 1996), we expect to find higher levels of heterozygosity if populations have a higher degree of asexuality. In agreement with this, a high heterozygosity level was observed in Sitobion species that were mainly or functionally asexual (Sunnucks et al, 1996; Simon et al, 1999; Wilson et al, 1999; Haack et al, 2000). The high level of heterozygosity found in the French population of our study further confirms this pattern since we have previously shown that asexual lineages are prevalent in this region (Dedryver et al, 2001).

\section{Conclusion}

Altogether, this study provides additional knowledge on three important aspects of the genetic structure of sexual and asexual populations in aphids. First, we showed here that, in agreement with the model's predictions, highly diverse sexual populations of $S$. avenae predominate under the continental climate of Romania, while few massively amplified asexual genotypes prevail under the oceanic climate of Western France. Therefore, our data give evidence that winter climate is a major force in structuring reproductive mode and genetic variation in aphids. Generalising these results would require studies on the effect of mild and harsh winters in a broader range of geographical localities. The second point concerns heterozygosity which differs greatly between sexual (CP) and asexual (OP) genotypes of $S$. avenae. While high heterozygosity is expected under long-term asexual reproduction (but also if asexual genotypes have a hybrid origin; see Delmotte et al, 2003), it remains to understand the sources for heterozygote deficit in sexual populations of $S$. avenae. Following the dynamics of sexual reproduction from the production of sexual forms to the hatching of new clones emerging from crosses would certainly help at resolving this problem. Thirdly, although aphid-plant relations were not the major theme of this paper, we showed that, in contrast with previous works reporting host-specialised genotypes in $S$. avenae (De Barro et al, 1995; Sunnucks et al, 1997), Romanian populations were not genetically differentiated according to their host plants. Whether the interplay between mode of reproduction and gene flow may affect local adaptation deserves further studies.

\section{Acknowledgements}

This work was supported by a grant of the FrenchRomanian collaborative teaching program TEMPUS. We are especially grateful to Manuel Plantegenest, Claude Rispe, Paul Sunnucks, Alex Wilson, and two anonymous reviewers for providing valuable comments on earlier version of this manuscript.

\section{References}

Baker HG (1965). Characteristics and modes of origin of weeds. In: Baker HG, Stebbins GL (eds) Genetics of Colonizing Species, Academic Press: New York, pp 137-172.

Bell G (1982). The Masterpiece of Nature: The Evolution and Genetics of Sexuality. University of California Press: Berkeley, USA.

Birky CW (1996). Heterozygosity, heteromorphy, and phylogenetic trees in asexual eukaryotes. Genetics 144: 427-437.

Blackman RL (1971). Variation in the photoperiodic response within natural populations of Myzus persicae Sulz. Bull Entomol Res 60: 533-546.

Caillaud CM, Via S (2000). Specialized feeding behavior influences both ecological specialization and assortative mating in sympatric host races of pea aphids. Am Nat 156: 606-621.

Carvalho GR (1994). Genetics of aquatic clonal organisms. In: Beaumont AR (ed) Genetics and Evolution of Aquatic Organisms, Chapman \& Hall: London. pp 291-323.

Cavalli-Sforza LL, Edwards AW (1967). Phylogenetic analysis: models and estimation procedures. Am J Human Genet 19: 233-257.

De Barro PJ, Sheratt TN, Brookes CP, David O, Maclean N (1995). Spatial and temporal genetic variation in British field populations of the grain aphid Sitobion avenae F. Hemiptera: Aphididae studied using RAPD-PCR. Proc $R$ Soc London $B$ 262: 321-327.

Dedryver CA (1987). Biologie, écologie et dynamique de population des pucerons des céréales en climat océanique. Thèse Sciences, Université Paris Sud Orsay.

Dedryver CA, Hullé M, Le Gallic JF, Caillaud M, Simon JC (2001). Coexistence in space and time of sexual and asexual populations of cereal aphid Sitobion avenae. Oecologia 128 379-388. 
Dedryver CA, Le Gallic JF, Gauthier JP, Simon JC (1998). Lifecycle of the aphid Sitobion avenae F. polymorphism associated with sexuality. Ecol Entomol 23: 123-132.

Delmotte F, Leterme N, Gauthier JP, Rispe C, Simon JC (2002). Genetic architecture of sexual and asexual populations of the aphid Rhopalosiphum padi based on allozyme and microsatellite markers. Mol Ecol 11: 711-723.

Delmotte F, Sabater B, Leterme N, Latorre A, Sunnucks P, Rispe C, Simon J-C (2003). Phylogenetic evidence for hybrid origins of asexual lineages in an aphid species. Evolution (in press).

Deng HW, Lynch M (1996). Change of genetic architecture in response to sex. Genetics 143: 203-212.

Dixon AFG (1985). Structure of aphid populations. Annu Rev Entomol 30: 155-174.

Dufresne F, Hebert PDN (1994). Hybridization and origins of polyploidy. Proc $R$ Soc London Ser B 258: 141-146.

Excoffier L, Smouse PE, Quattro JM (1992). Analysis of molecular variance inferred from metric distances among DNA haplotypes: application to human mitochondrial DNA restriction data. Genetics 131: 479-491.

Goudet J (1995). FSTAT version 1.2. A computer program to calculate F-statistics. J Hered 86: 485-486.

Haack L, Simon JC, Gauthier JP, Plantegenest M, Dedryver CA (2000). Evidence for predominant clones in a cyclically parthenogenetic organism provided by combined demographic and genetic analyses. Mol Ecol 9: 2055-2066.

Hales DF, Tomiuk J, Wöhrmann K, Sunnucks P (1997). Evolutionary and genetic aspects of aphid biology: a review. Eur J Entomol 94: 1-55.

Hand SC (1983). The effect of temperature and humidity on the duration of development and hatching success of eggs of the aphid, Sitobion avenae. Entomol Exp Appl 33: 220-222.

Hand SC (1989). The overwintering of cereal aphids on Gramineae in southern England, 1977-1980. Ann Appl Biol 115: 17-29.

Hebert PDN (1987). Genotypic characteristics of cyclic parthenogens and their obligately asexual derivatives. In: Stearns $S$ J (ed) The Evolution of Sex and its Consequences, Birkhaüser Verlag: Basel, Switzerland. pp 175-195.

Loxdale HD, Tarr IJ, Weber CP, Brookes CP, Digby PG, Castañera P (1985). Electrophoretic study of enzymes from cereal aphid populations. III - spatial and temporal genetic variation of Sitobion avenae F. Hemiptera: Aphididae. Bull Entomol Res 75: 121-141.

Lynch M (1984). Destabilizing hybridization, general-purpose genotypes and geographic parthenogenesis. Q Rev Biol 59: 257-290.

Lynch M, Spitze K (1994). Evolutionary genetics of Daphnia. In: Real L (ed) Ecological Genetics, Princeton University Press: New Jersey. pp 109-128.

Miyazaki M (1987). Forms and morphs of aphids. In: Minks AK Harrewijn P (eds) Aphids, their Biology, Natural Enemies and Control, Elsevier: Amsterdam. pp 27-50.

Mogie M (1986). On the relationship between asexual reproduction and polyploidy. J Theor Biol 122: 493-498.

Moran NA (1992). The evolution of aphid life cycles. Annu Rev Entomol 37: 321-348.

Newton C, Dixon AFG (1988). A preliminary study of variation and inheritance of life history traits and the occurrence of hybrid vigour in Sitobion avenae F. Hemiptera: Aphididae. Bull Entomol Res 78: 75-83.

Nei M (1978). Estimation of average heterozygosity and genetic distance from a small number of individuals. Genetics 89 : 583-590.

Parker Jr ED, Niklasson M (1999). Genetic struture and evolution in parthenogenetic animals. In: Singh RS, Krimbas CB (eds) Evolutionary Genetics: From Molecules to Morphology, Cambridge University Press: Cambridge. pp 456-474.

Pons X, Comas J, Albajes R (1995). Occurrence of holocyclic and anholocyclic populations of Rhopalosiphum padi and Sitobion avenae (Hom.: Aphididae) in the northeast of Spain. J Appl Entomol 119: 171-175.

Raymond M, Rousset F (1995). Genepop, a population genetics software for exact tests and oecumenicism. I Hered 86: 248249.

Rice WR (1989). Analyzing tables of statistical tests. Evolution 43: 223-225.

Rispe C, Pierre JS (1998). Coexistence between cyclical parthenogens, obligate parthenogens, and intermediates in a fluctuating environment. I Theor Biol 195: 97-110.

Rispe C, Pierre JS, Simon JC, Gouyon PH (1998). Models of sexual and asexual coexistence in aphids based on constraints. J Evol Biol 11: 685-701.

Rousset F (1997). Genetic differentiation and estimation of gene flow from $F$-statistics under isolation by distance. Genetics 145: 1219-1228.

Schneider S, Klueffer JM, Roessli D, Excoffier L (2000). Arlequin ver. 2000: A Software for Population Genetic Data Analysis. Genetics and Biometry Laboratory, University of Geneva. Switzerland.

Simon JC, Baumann S, Sunnucks P, Hebert PDN, Pierre JS, Le Gallic JF et al (1999). Reproductive mode and population genetic structure of the cereal aphid Sitobion avenae studied using phenotypic and microsatellite markers. Mol Ecol 8: 531545.

Simon JC, Leterme N, Delmotte F, Martin O, Estoup A (2001). Isolation and characterisation of microsatellite loci in the aphid species, Rhopalosiphum padi. Mol Ecol Notes 1: 4-5.

Sunnucks P, De Barro PJ, Lushai G, Maclean N, Hales DF (1997). Genetic structure of an aphid studied using microsatellite: cyclic parthenogenesis, differentiated lineages, and host specialization. Mol Ecol 6: 1059-1073.

Sunnucks P, England PR, Taylor AC, Hales DF (1996). Microsatellite and chromosome evolution of parthenogenetic Sitobion aphids in Australia. Genetics 144: 747-756.

Sunnucks P, Hales DF (1996). Unmerous translated sequence of mitochondrial cytochrome oxidase I-II in aphids of the genus Sitobion (Hemiptera: Aphididae). Mol Biol Evol 13: S10-S24.

Vandel A (1928). La parthénogenèse géographique: contribution à l'étude biologique et cytologique de la parthénogenèse naturelle. Bull Biol France Belg 62: 164-281.

Weir BS, Cockerham CC (1984). Estimating F-statistics for the analysis of population structure. Evolution 38: 1358-1370.

Wilson AC, Sunnucks P, Hales DF (1999). Microevolution, low clonal diversity and genetic affinities of parthenogenetic Sitobion aphids in New Zealand. Mol Ecol 8: 1655-1666. 